satisfied, so far as I can see, by a group formed from the disper. sion of a comet by Jupiter, or other large planet. If the frag. ments of the comet leave the neighbourhood of Jupiter, they should after each revolution return nearly to the same point in space. But a radiant area $8^{\circ}$ or $10^{\circ}$ long. on the night of November 27 , implies a distribution of the aphelia over $10^{\circ}$ or $12^{\circ}$ of longitude, or a similarly large difference of major axes. Such orbits can hardly have a common point at a great distance from the time upon a body moving in an orbit inclined several degrees to the ecliptic should, it would seem, be incompatible with a grouping at the earth's node.

"Again, suppose that a disrupted body or agglomeration has been once changed into a stream by the differential action of gravitation in the manner shown so beautifully by Schiaparelli. If the perturbing forces exerted by any planet or planets, whether temporary or long continued, should produce such differences of major axes, or longitudes of perihelia, by differential action, the total action would, undoubtedly, entirely scatter the group at the earth's nodes.

"In fact, instead of regarding the meteors as a stream, we ought rather to look upon the group as coming together near the perihelion-or near the node-and then scattering widely, to reassemble, perhaps, after a complete revolution in the orbit.

"A resisting medium cannot account for the observed effect, for this does not change the longitude of the perihelion of the orbit.

"It seems to me, therefore, that the periodic meteors cannot have been brought into the solar system as a stream, but that the forces which have scattered the comets are those acting near the perihelia of their orbits. As a probable corollary, we may infer that whatever force divided Biela's comet into its two principal parts was one acting near the perihelion.

"If we consider the orbits of the meteors of November 14, the preceding discussion is simplified. That shower is sharply limited, being in its greatest intensity only one or two hours long. Its recurrence at regular intervals of one third of a century, for nearly a thousand years, precludes great differences of the major axes of the individual orbits, and the secular procession of the node of the group, as a group, equally forbids great differences of inclinations of the orbits.

"The size of the radiant is therefore due almost exclusively to the difference of the longitude of the perihelia. This difference for that group cannot be less than $15^{\circ}$.

"In conclusion I would say that we have no evidence, as yet, that any radiant of meteors is so small as is apparently required by the supposition of the distinguished Italian astronomer, that the meteors were drawn as a stream into the solar system from the stellar spaces, With Prof. Weiss and others, I am inclined to consider them all to have been once connected with periodic comets. The scattering took place apparently at or near the perihelion."

\section{THE NATIONAL HERBARIA}

THE following memorial has been transmitted to the First Lord of the Treasury on the above subject :-

"To the Right Hon. W. E. Gladstone, First Lord of the Treasury.

"SIR, - The undersigned persons engaged in the pursuit of botany, or in instruction therein, desire to call your serious attention to a subject that deeply concerns the progress of Natural Science, and that of those branches of agriculture, horticulture, forestry, and manufactures that largely depend on botanical research.

"The First Commissioner of Works, in a Memorandum presented to Parliament before the close of last session, clearly raised the question whether it is desirable to transfer to the branch of the British Museum about to be constructed at South Kensington the Scientific Collections and Library now existing at Kew, and further stated that, pending the decision on that subject, he considers it his duty to take care that no new expense shall be incurred at Kew which will embarrass the Ministers of the Crown or the House of Commons in arriving at a decision.

"The Lords of the Treasury, in their Minute of the 24th July, decline to refer to that portion of the above-mentioned Memorandum, and no statement on that subject has since been made by any Minister of the Crown which shows whether it has received the attention of the Government.
"Being strongly of opinion that the proposed measure would be highly detrimental to the progress of scierce, and injurious to all those interests that depend upon it, we beg to urge upon you that the subject is not one merely of departmental interest, and that it would not be unfitting your position, as First Minister of the Crown, to give your consideration to the following reasons which we beg to urge in opposition to the proposed measure :-

" $\mathrm{I}$. That it appears to us that it is absolutely necessary that a great Botanical Garden like that at Kew, which is confessedly far the most important in the world, should be in close connection with as perfect an Herbarium and Botanical Library as possible, and that these conditions are now fulfilled as far as circumstances and the present state of science will admit.

" 2 . That such a combination of living and dead specimens is requisite for the complete study of plants, as regards their techni$\mathrm{cal}$, physiological, and economic characters; and that the removal of the Herbarium would be a retrograde step in a scientific point of view.

" 3 . That the records of the Colonial and India Offices will show of what immense importance the establishment at Kew has been to the welfare of the entire British Empire, and that weighty questions are constantly submitted to the Director which require immediate attention, and which could not, in many cases, be satisfactorily answered without reference to the Library or Herbarium.

"4. That every facility for the investigation of the intimate structure and general habits of plants, and the study of them in every point of view which can reasonably be considered within the scope of pure Botany, is afforded by the Herbarium and Museum of Botany in connection with the Garden, and that it would be easy to point out important labours in that direction which have been instituted at Kew, while the systematic treatment has always regarded the more minute characters as well as those which are superficial.

" 5. It has been remarked, indeed, that important works, such as the 'Hortus Kewensis,' have been prepared without the aid of an Herbarium at Kew. We would, however, remark that the statement is not correct, as there was an Herbarium, which was dispersed before Sir W. Hooker became Director ; and the conditions of Natural Science are at the present time so completely altered that it is impossible to institute any fair com parison, the number of known species being enormously increased since the date of the publication in question.

"6. That the Museums of Structural and Economic Botany, which owe their existence and importance to the late Sir W. Hooker, are often found of great value in the deci-ion of critical points in the study of species, and that the severance of them from the Herbarium and Library would be a serious loss.

"7. That in the principal Botanic Gardens on the Continent, where effective work is done, there is in every case a large herbarium connected with them.

"8. That, in the interest of Botanical Science, we think it highly desirable that, besides the collections now existing at Kew, an Herbarium, or collection of dried plants, as complete as posible, should be maintained in connection with the Natural History Museum which it is proposed to place at South Kensington, and that the two Herbaria should be in intimate relation with each other.

"9. That from the delicate and perishable nature of its contents, and the necessity of referring to numerous specimens, an Herbarium cannot be made use of by many persons at the same time; and while it is desirable that students should have ready means of access at the National Museum in London to collections which may enable them to identify the plants of any particular country, it is still more essential that the aullors of important works in Botanical Science should be enabled, as at present, to pursue their labours at Kew without interruption from casual visitors.

"I0. That an Herbarium is the least costly of all collections of Natural History, and that which requires the least amount of space for its proper maintenance, in proportion to the number of objects which it contains.

"II. That the arrangements of the Herbarium at Kew are so perfect, and the facilities for study so great, that it is resorted to from all parts of the world ; and it would therefore be unwise to make a change which in the result is almost certain to be detrimental, and which, we are assured, would be especially distasteful to the leading foreign botanists.

"M. J. Berkeley, F.L.S., Botanical Director to the Royal 
Horticultural Society ; Charles C. Babington, F.R.S., Professor of Botany, Cambridge; M. A. Lawson, F.L.S., Professor of Botany, Oxford; I. H.Balfour, M.D., F.R.S., Professor of Botany, Edinburgh; Alexander Dixon, M.D., Professor of Botany, Glasgow; G. Dickie, M.D., F.L.S., Professor of Botany, Aberdeen; E. Perceval Wright, M.D., F.L. S., Professor of Butany, Dublin ; Robert Bentley, F.L.S., Professor of Butany, King's College and Pharmaceutical Society of Great Britain; W. T. Thiselton Dyer, B.Sc., F.L.S., Professor of Botany, Royal Horticultural Society, London; R. O. Cunningham, M.D., F.L.S., Professor of Botany and Zoolouy, Bellast; W. R. McNab, M.D., Professor of Botany, Royal College of Science, Dublın; George Henslow, F.L.S., Lecturer at St. Bartholomew's Hospital and Royal Agricultural College, Cirencester; John Ball, F.R.S. ; Maxwell T. Masters, M.D., F.R.S.; James Bateman, F.R.S.; R. Trevor Clarke, F.R.H.S. ; W. Wilson Saunders, F.R.S.; Geo. F. Wilson, F.R.S.; Rohert Hogg, LL.D., F.L.S., Pomological Director to therRoyal Horticultural Society ; W. Sowerby, F.L.S. ; D. Moore, Ph.D., F.L.S. ; Andrew Murray, F.L.S. ; William Munro, Major-General, C.B., F.L.S.; M. Pakenham Edgeworth, F.L.S. ; John Miers, F.R.S., V.P.L.S. ; Frederick Currey, F.R.S., Sec. L.S.; Daniel Hanbury, F.R.S., F.L.S. ; C. E. Broome, F.L.S. ; Leonard B.omefield, F.L.S.; J. T. Boswell Syme, LL.D., F.L.S. ; Hugh Cleghorn, M.D., F.L.S.; Clements Markham, C.B., F.L.S.; R. C. A. Prior, M.D., F.L.S. ; Edward J. Waring, M.D., F.L.S.; George C. M. Birdwood, M.D.; Walter Elliot, K.C.S.I., F.L.S. ; J. Forbes Watson, M.D., F.L.S. ; Richard Strachey, Major-General, C.S.I., F.R.S. ; E. W. Cooke, R.A. F.R.S. ; Robert Braithwaite, M.D. ; William Mitten, A.L.S.; W. Allport Leighton, F.L.S.; William Phillips; John Goucher, F.L.S. ; J. Leicester Warren; Worthington G. Smith, F.L.S. ; M. C. Cooke; James M. Crombie, F.L.S. ; Alfred W. Bennett, F.L.S. ; V. G. More, F.L.S. ; Thomas Moore, F.L.S., Floricultural Director to the Royal Horticultural Society ; Thomas Thomson, M.D., F.R.S., Jate Superintendent Royal Botanic Garden, Calcutta ; Charles Darwin, F.R.S.; George Bentham, F.R.S.

\section{SCIENTIFIC SERIALS}

THE Fournal of Botany for November, 1872 , commences with a paper by Prof. Thiselton-Dyer, on an intricate point of vegetable histology, "Tyloses," or the cellular filling-up of vessels, with a plate. Critical botany is represented by two articles, on Dasylirion and Beaucarnea, by Mr. J. G. Baker, and notes on some Scandinavian plants, by Dr. Trimen; and geographical botany also by two- "The Influence of Insect Agency on the Distribution of Plants," by Mr. A. W. Bennett, and notes respecting some Birmingham plants, by Mr. Jas. Bagnall. Among the extracts is a very interesting one on some southern plants observed in the environs of Paris in 1871 , being an account of the species added to the flora of the neighbourhood of Paris by the German invasion, amounting to 190 . In the December number Dr. Trimer records and draws a recent addition to the British flora, Psamma baltica; and the whole of the remaining original articles relate to cryptogamic botany-the Rev. Jas. Crombie discourses on lichens, the Rev. P. O'Meara on Diatoms, Mr. J G. Baker, on a new Asplenium from Cape Colony, and $\mathrm{H}$. Boswell, on the mosses of Oxfordshire. A large portion of the number for January, 1873 , is occupied by a lengthy and iuteresting biography, accompanied by a portrait of the African traveller, $\mathrm{F}$. Welwitsch. The remaining original articles include a contribution to the subject of the "Influence of Insect Agency on the Distribution of Plants," by Dr. Buchanan White, a valuable and suggestive paper by Prof. M'Nab, and a description by $\mathrm{Mr}$ J. G. Baker of some new ferns from Lord Howe's Island. The short "Notes and Queries" are not the least interesting part of these three numbers.

\section{SOCIETIES AND ACADEMIES LONDON}

Royal Society, Jan. 9.- "Further Remarks on the Sense of Sight in Birds," by Robert James Lee, M.A., M.D. He thinks it would be premature to enter upon general deductions until the data we possess are more numerous, and the anatomical details are generally allowed to be correct. Since his last communica- tion he has received much assistance and valuable information from Mr. Hulke, who has directed considerable attention to the structure of the ciliary muscle in birds. In order to show the different degrees of development of the ciliary muscle, he drew up a short table containing those specimens which have been examined with most attention. For the present he considers the ciliary muscle as a simple structure for the production of one effect, whatever minute differences may exist in the internal arrangement of its fibres. According to the table the axis of vision in the Eagle Owl is 3.7 ; Vulture, 3.I ; Buzzard, 4; Rhea americana, 3; Flamingo, 9; Penguin, 6; Andean Goose, 4 ; Vieillot's Pheasant, 6; Wood Francolin, 46; Canada Goose, 5 ; Hawk-headed Parrot, 4; Spotted Dove, 7; Grouse, 4; Partridge, 4. A second table is a continuation of that commenced in his last communication, and is intended to furnish certain data wh ch are necessary for the determination of the visual powers in various species of birds.

"On the Union of Ammonia Nitrate with Ammonia." By Edward Divers, M.D.

Ammonia nitrate deliquesces in ammonia gas at ordinary temperatures and pressures, forming a solution of the salt in liquefied ammonia. To prepare the product, it is only requisite to pass dry ammonia gas into a flask containing the dry nitrate; but the condensation proceeds more rapidly if the flask is surrounded with ice. The liquid obtained varies in composition according to the temperature and pressure. The liquid boils when heated, and, when nearly saturated with nitrate, deposits crystals of it when cooled-just like an aqueous solution. It can also, like an aqueous solution, be heated above its boiling-point without boiling, and become supersaturated with the salt without crystallising. When poured out into an open vessel, it becomes almost instantly gelatinous in appearance-may, indeed, become so as it falls in a stream from the flask containing it. This effect is due to evaporation of ammonia and solidification of nitrate at the surface of the liquid; on breaking the crust of nitrate, the compound flows out as liquid as ever. It is not caustic to the dry skin. During its decomposition cold is manifested, and during its formation heat is evolved, but not to a great extent, because the heat given out by the liquefaction of the ammonia is nearly all used up in the liquefaction of the nitrate. Its specific gravity can be calculated from its composition, by taking for the purpose $1524^{\prime} 5$ as the specific gravity of the nitrate, and $67 \mathrm{I}$ as that of the ammonia. In its rate of expan. sion by heat, the liquid resembles others that exist as such at ordinary temperatures, rather than those that, like ammonia itself, 'are only retained as such by great pressure. Its expansivity increases with the quantity of ammonia present. Its action' upon a great number of substances, principally inorganic, has been tried, and found to be for the most part like that of ammonia (in the absence of water) and ammonia nitrate conjoined. The nitrate appears to undergo double decomposition with most salts, and the ammonia to unite with nearly all of them, including those of magnesium, aluminium, iron, and manganese. It is a good electrolyte, ammonia and hydrogen appearing at the negative electrode, and nitrogen and ammonia nitrate at the positive electrode.

Anthropological Institute, Jan. 7.-Sir John Lubbock, Bart., F.R.S., in the chair. A paper by the late J. W. Jackson was read on the Atlantean Race of Western Europe. The chief aim of the author was to controvert the largely accepted opinion that the dark Atlantean race was of Turanian origin. A paper by Dr. John Shortt on the Kojahs of Southern India. The true Kojahs or Eunuchs are chiefly seen about the houses of wealthy Mussulman nobles, by whom they are placed at the head of their harems. Sometimes they hold important charges with a considerable amount of control. The ladies of the harem look upon them as their confidential advisers in all matters relating to their personal concerns. The second class of Eunuchs are called Higras or natural Eunuchs, who dress like and ape the manners of women, and are for the most part utterly worthless characters. The paper entered into minute details respecting the physical characters and habits of that strange class of men. $-A$ joint paper by $M$. H. Gerber and Capt' Butler on the Primordial Inhabitants of Brazil, was also read." It contained valuable and full statistical information as to the populations of the provinces; the occupations of the inhabitants, their industry and productions; the mineral wealth of the country, agriculture, manufactures, and colonisation. 